8 Милостивая А. И. Селебрити как персонаж масс-медийного нарратива (на материале статей о Ким Кардашьян) // Научный диалог. 2017. №8.

9 Карпов И.А., Крячков А.Ф. Приемы изложения рекламной информации. В сборнике: Современные тенденции в науке Сборник статей Международной научно-практической конференции. 2017. С. 9-13.

10 Шиловский С.В. Использование лидеров мнений в коммуникациях розничной сети в сойиальных медиа. Практический маркетинг. 2018. № 11 (261). С. 18-24.

11 Санникова К.А., Домарацкая Е.A. Influencer Marketing: сущность, оценка и прогноз рынка, проблемы и рекомендации. Социально-экономическое управление: теория и практика. 2019. № 4 (39). С. $42-47$.

\title{
INFLUENCER MARKETING AS ONE OF THE MODERN MARKETING TRENDS
}

\author{
(C) 2020 Karpov Ivan Alekseevich \\ Candidate of economic Sciences, associate Professor \\ (c) 2020 Kryachkov Alexander Fyodorovich \\ Candidate of economic Sciences, associate Professor \\ Samara State University of Economics \\ E-mail: karpovivan79@yaridex.ru, kryachkov.aleksandr@mail.ru
}

Keywords: marketing communications, Influencer Marketing, recommendation marketing, celebrity marketing.

The article describes some trends in modern marketing, examines the concept of "Recommendation marketing", the prerequisites for its development.

УДК 65.011 .56

Код РИНЦ 9295-8227

\section{ПРОГРАММНЫЕ ПРОДУКТЫ УПРАВЛЕНИЯ ЛОГИСТИЧЕСКИМИ ПРОЦЕССАМИ}

\author{
(c) 2020 Карпова Наталья Петровна \\ доктор экономических наук, доцент, профессор \\ (C) 2020 Сиразетдинова Нелли Ринатовна \\ студент \\ Самарский государственный экономический университет \\ E-mail: natk08@rambler.ru
}

Ключевые слова: логистика, логистическая система, программное обеспечение, системы управления базами данных, эфффективность, оптимизация, поставки.

Статья посвящена анализу современных программных продуктов, используемых в управлении материальными потоками в логистических системах; выявлению их преимуществ и недостатков, а также источников повышения эфффективности управления логистическими процессами предприятий. 
В современном мире все больше и больше набирает обороты такая сфрера деятельности, как логистика. Она становится все популярней среди предпринимателей, и почти в каждой компании наблюдается тенденция автоматизации логистических процессов за счет создания специального программного обеспечения (ПО), которое упрощает работу логистических систем компаний, повышает их эффрективность и, соответственно, уменьшает продолжительность логистического цикла.

Существует различное множество программных продуктов, нашедших свое применение в логистике. Самой простой является программа, которая используется и в повседневности обычными пользователями. Это программа Excel. Она достаточно проста в использовании и является хорошим инструментом для создания рабочих таблиц, а также не требует найма программистов.

Но в каждой системе есть свои минусы. Также и в Ехсеl есть один весомый минус, который мешает работе - это объем информации. Чем больше объем, тем сложнее работать с этой программой. Получаемые в Excel таблицы являются "плоскими" в использовании. Для более понятного и подробного объяснения приведем пример на обычных учебниках. Так, в каждом учебнике есть параграфы, в каждом параграфе есть главы, а в каждой главе есть определенные строчки. Таким образом, мы получаем несколько уровней иерархии информации. Количество глав, параграфов и строк может доходить до сотен, тысяч и так далее. Теперь стоит перевести этот пример на заключение обычных договоров, которые имеют такую же структуру иерархий. Именно на этом этапе становится затруднительно работать с этой программой, так как в ней уже труднее расширить информацию и отобразить то, что находится внутри этих "строк" - договоров. Точнее, это возможно сделать, но уже будет увеличиваться шанс на ошибку, так как пользователю будет сложнее работать с таким объемом информации, не сжатым. В процессе планирования поставок пользователю приходиться создавать огромную кучу файлов с большим количеством вкладышей, что также затрудняет работу в Exсеl. Подводя итоги по этой программе, можно сказать, что работать в Excel с большим массивом данных неудобно. Она не позволяет сотрудникам выполнять работу быстро и качественно.

Теперь речь пойдет о программах СУБД (Система Управления Базами Данных). Это такие программы, которые связанны между собой таблицами. С помощью этого можно видеть несколько таблиц одновременно и с легкостью переходить от одной таблицы к другой. Такая возможность может привести к поистине прекрасным результатам на практике и улучшить эффективность работы сотрудников. Снова приведем пример: наша компания находит поставщика и заключает с ним договор. В дальнейшем этот договор дополняется новыми условиями. В данном ПО это выглядит так: в одной таблице содержатся договоры, во второй условия этого договора (размер транспорта, объем перевозимого груза, вид транспорта, особые указания по перевозке груза и т.д.). Все эти таблицы имеют связь и, к примеру, можно создать из таблицы договоров новую таблицу с условиями этого договора, а затем спокойно открыть и увидеть условия этого договора.

Благодаря этому можно написать о главном преимуществе данного ПО СУБД - это скорость и точность использования информации, а также достаточно комфортная работа. Также надо отдать должное, что работа в таких программах возможна в единой системе 
информационного пространства, то есть ей могут пользоваться несколько сотрудников компании одновременно.

Перейдем к реальным примерам СУБД. Первый пример - это MySQL. Это достаточно популярная база данных в современном мире, которая используется на таких известнейших ресурсах как Facebook, Twitter и You TUBE. Она прославилась за счет своей простоты и надежности в применении. Также эта система очень гибкая и имеет огромный выбор различных таблиц для различной информации.

Второй пример - это MS SQL Server. Это СУ (система управления) математической базой данных компании Microsoft. Она сделана специально для их компании. Применяется для всех видов данных (от персональных до более крупных данных компаний).

И напоследок приведем пример тоже достаточно известной СУБД- Oracle Database. Эта система управления базами данных славится простой документацией, а также легкостью обработки больших данных.

Обеспечение своих предприятий такими или похожими базами данных достаточно не дешевый и не быстро внедряемый проект, поэтому не каждая компания может себе позволить такие системы. В основном такие системы внедряются в крупные компании, численность сотрудников в которых более 1000 человек, дабы упростить и улучшить работу логистических систем.

Существует и третья вариация ПО для предприятий - это создание собственных, индивидуальных СУБД для каждой конкретной организации. Давайте же разберемся, каким образом можно создать свою программу. Первый и самый простой вариант - нанять сотрудника-программиста для создания нужного ПО в компании. Такой процесс очень трудоемкий и требует личного присутствия руководителей во время создания программ для более качественного объяснения концепции программы. Задача программиста - создать программное решение, с которым можно выполнять основные поставленные задачи. Здесь важно учитывать простоту программирования для более простого использования в дальнейшем. Насколько качественная программа, можно понять только спустя какое-то время, когда она запустится в действие. В случае обнаружения недостатков потребуется ее доработка, что сопряжено с дополнительными расходами.

Второй вариант - заключить договор с организацией, занимающейся созданием/написанием таких систем для различных клиентов. Важно запросить понятную, доступную программу, которой смогут пользоваться все сотрудники компании, без исключения. Данный способ более проверенный, немного быстрее и при этом более дорогой. Но за эти деньги можно сохранить свое время, потраченное на доработку нужного ПО.

Резюмируя выше сказанное, стоит отметить, что рассмотренные программные продукты, используемые в логистической деятельности организаций, имеют схожесть в простоте исполнения, при этом они разнятся по стоимости и кругу решаемых проблем. Любые из представленных программных продуктов помогают решать поставленные задачи в логистической деятельности предприятий:

- Оптимизация производственных процессов;

- Сокращение времени обработки заказа;

- Увеличение конкурентоспособности компании на рынке; 
- Увеличение качества контроля над плановыми показателями (заданиями);

- Повышение качества представляемых услуг;

- Увеличение эффективности работоспособности сотрудников.

Важно понимать, что для качественной деятельности компаний, необходимо максимально упрощать работу с базами данных для быстрых сделок и быстрого поиска информации. Это поможет всем компаниям не потерять своих драгоценных клиентов, повысить спрос на их продукты, и, конечно же, обеспечить по максимуму эфффективность работы логистических систем.

1 Герберт Шилдт. CLR via C\# программирование на платформе Microsoft .NET FRAMEWORK. СПб: Питер, 2019. - 896 c.

2 Костышева Я.В.Эффективность применения программных обеспечений в области транспортной логистики" // Экономикс, 2013. - №1. - С. 47-55.

3 Левкин Г.Г., Никифоров О.А. Информационное обеспечение процессов логистической системы предприятия // Проблемы современной науки и образования, 2017. - №3. - С. 93-95.

4 Карпова Н.П. Обоснование необходимости внедрения системы управления складом / Н.П. Карпова, М.М. Усачева// Вестник молодых ученых Самарского государственного экономического университета. - 2017. - № 1. - С. 169-171. - 0,4 / 0,3 печ. л. // https://elibrary.ru/item.asp?id=29237829

${ }^{5}$ Karpova N. P. Strategic Supply Management in the Logistics Systems of Industrial Enterprises / N. P. Karpova, T. E. Evtodieva, I. A. Toymentseva // Advances in Economics, Business and Management Research, volume 47, International Scientific Conference "Far East Con" (ISCFEC 2018). January 2019. p.p. 452-454 // https://www.atlantis-press.com/proceedings/iscfec-18/55912438. - 0,6 / 0,2 печ. л. https://doi.org/10.2991/iscfec-18.2019.115

\title{
SOFTWARE PRODUCTS FOR MANAGING LOGISTICS PROCESSES
}

\author{
(C) 2020 Karpova Natalia Petrovna \\ Doctor of Economics, Associate Professor, Professor \\ (C) 2020 Sirazetdinova Nelly Rinatovna \\ Student \\ Samara State University Of Economics \\ E-mail: natk08@rambler.ru
}

Keywords: logistics, logistics system, software, database management systems, efficiency, optimization, delivery.

The article is devoted to the analysis of modern software products used in the management of material flows in logistics systems; identification of their advantages and disadvantages, as well as sources for improving the efficiency of logistics processes management in enterprises. 